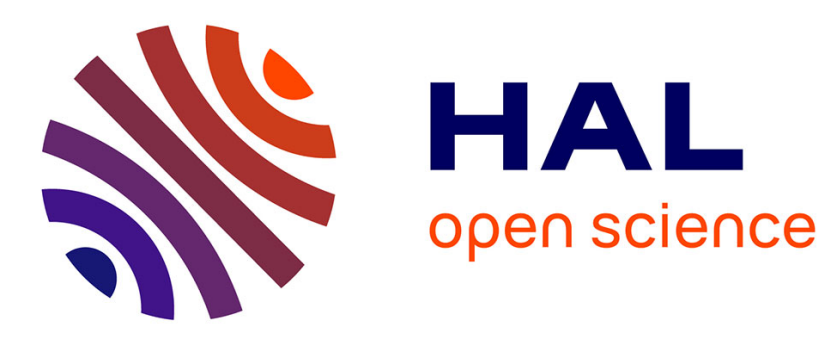

\title{
Lattice Transitions and Flickering Images in Aged Cu-Mn Alloys
}

J. Perkins, K. Adachi, T. Yamashita

\section{To cite this version:}

J. Perkins, K. Adachi, T. Yamashita. Lattice Transitions and Flickering Images in Aged Cu-Mn Alloys. Journal de Physique IV Proceedings, 1995, 05 (C8), pp.C8-161-C8-166. 10.1051/jp4:1995820 jpa00254069

\section{HAL Id: jpa-00254069 https://hal.science/jpa-00254069}

Submitted on 1 Jan 1995

HAL is a multi-disciplinary open access archive for the deposit and dissemination of scientific research documents, whether they are published or not. The documents may come from teaching and research institutions in France or abroad, or from public or private research centers.
L'archive ouverte pluridisciplinaire HAL, est destinée au dépôt et à la diffusion de documents scientifiques de niveau recherche, publiés ou non, émanant des établissements d'enseignement et de recherche français ou étrangers, des laboratoires publics ou privés. 


\title{
Lattice Transitions and Flickering Images in Aged Cu-Mn Alloys
}

\author{
J. Perkins, K. Adachi* and T. Yamashita** \\ Monterey Institute of Advanced Studies, P.O. Box 975, Monterey, CA 93942-0975, U.S.A. \\ * Sumitomo Metal Mining Co., Central Research Lab., Ichikawa 272, Japan \\ ** Naval Postgraduate School, Materials Science Group, Monterey, CA 93943, U.S.A.
}

\begin{abstract}
Distinctive "flickering" movements are observed in TEM images of the microstructure of $\mathrm{Cu}-\mathrm{Mn}$ alloys after aging within the miscibility gap. Analyses of two-beam image extinction and electron diffraction streaks indicate that the underlying tweed and "V-shaped" images involve a static displacement field of the type $\{110\}<1 \overline{10}\rangle$. Atomic force microscopy and other microanalyses show the presence of Mn-enriched colonies of $15-40 \mathrm{~nm}$, formed throughout the microstructure, in which twinned fct crystallites are induced and confined. The flickering movements are interpreted as a direct manifestation of the fec $\Rightarrow \mathrm{fct}$ transformation event and in particular of a rotation of the fct $\mathrm{c}$-axis, these effects being caused by an inelastic interaction between $\langle 110\rangle\langle 1 \overline{1} 0\rangle$ phonons and the accelerated electrons of the incident TEM beam.
\end{abstract}

\section{INTRODUCTION}

In $\mathrm{Cu}-\mathrm{Mn}$ alloys of nearly stoichiometric composition, aging inside the miscibility gap causes phase decomposition of the $\gamma$-fcc solid solution into Mn-rich and Mn-poor regions [1-3]. As well, near the Mnrich end of the $\mathrm{Cu}-\mathrm{Mn}$ system it is well-known that an $\mathrm{fcc} \Rightarrow \mathrm{fct}$ diffusionless transformation $[4,5]$ and a paramagnetic $\Rightarrow$ antiferromagnetic transition [6] take place upon cooling. Technologically, a combination of the phase decomposition during aging and the lattice transitions upon cooling form the basis of high damping capacity [1-3], and microstructurally they enable a remarkable dynamical effect in TEM called "flickering" [7,8], which occurs in tweed and other characteristic contrast images.

"Flickering" consists of repetitive and consistent contrast movements at specific locations, with the extent of the relevant contrast, both in terms of the scale of the feature and the amount of movement, being on the order of 5 to $20 \mathrm{~nm}[7]$. However, detailed examinations of the microstructure and interpretation of this unusual dynamical effect have not yet been reported. While a more comprehensive report has been prepared for dissemination elsewhere [9], a condensed outline of the analysis and the resultant hypothesis regarding the flickering effect is presented here.

\section{EXPERIMENTAL}

In the present work, the procedures by which $53.1 \% \mathrm{Cu}-44.8 \% \mathrm{Mn}-1.6 \% \mathrm{Al}(\mathrm{wt} . \%$ ) alloys were aged and thin-foils prepared for TEM observation were as reported previously [7]. It is noted that because of the twophase character of the aged alloys and the occasional presence of $\alpha$ - $\mathrm{Mn}$ particles at longer aging times, conventional electropolishing procedures were unable to produce the requisite brilliancy of thin-foil surfaces. Thus, a two-stage electropolishing procedure was developed, although this method still leaves slight microscale irregularities on the surface, as shown later.

A Digital Instruments "Nanoscope III" scanning probe microscope was used in a tapping mode to monitor the surface topography. A Hitachi IMA-3 secondary ion mass spectrometer (SIMS) was used with $\mathrm{Cs}^{+}$primary ions to inspect the composition profile in the direction of the specimen depth. The approximate sputtering rate may be estimated from that for pure $\mathrm{Cu}$, about $10 \mathrm{~nm} / \mathrm{min}$. TEM observations were made using JEOL JEM-120CX and JEM-2000EX microscopes. 


\section{RESULTS AND DISCUSSION}

Aging at $723^{\circ} \mathrm{K}$ for longer than 5 hours develops a remarkable microstructure in TEM images, which contains dashed, V-shaped, or W-shaped contrast features aligned in similar orientations, as shown typically in Fig. 1(a). This microstructure, which we may term "V-shaped" images, is obtained at a more advanced stage of aging than an earlier stage that produces striated tweed contrast; the latter appears at lower aging temperatures or shorter aging times.

\subsection{Image extinction and diffraction features of $V$-shaped images}

In the V-shaped images, the bisector of the V-angles is always lying along the trace of $\{110\}$ planes. In Fig. 1 (a) is shown an example with two V-alignment directions. One of these disappears when the $0 \overline{2} 2$ reflection is excited, as shown in Fig. 1(b). Various two-beam image analyses indicate that the V-shaped images follow the same extinction rules which apply to tweed microstructures [10]. The image extinction is well explained by assuming a static displacement field on $\{110\}$ planes in $\langle 1 \overline{1} 0\rangle$ directions, with image extinction occuring when the displacement direction involved in the image is exactly perpendicular to the $\mathrm{g}$ vector. For example, the two V-alignment directions observed with $\mathrm{g}=020$ excitation near [100] orientation, as in Fig. 1(a), are associated with (011)[011] and (011)[011] shear displacements, respectively. Of these, the one with (0I1)[011] vanishes for the $g=0 \overline{2} 2$ excitation condition of Fig. $1(\mathrm{~b})$, since the g-vector is normal to the shear direction.

The diffraction characteristics have also been examined to confirm the close analogy between the Vshaped images and conventional tweed contrast in TEM images. The $\langle 110\rangle *$ relrods, with the extinction rule that two for $\{h 00\}$, one for $\{h h 0\}$ and three for $\{h h h\}$ reflections do not appear [10], are observed exactly as reported for tweed micro-structures. The $\langle 110\rangle^{*}$ relrods are formed owing to a shear displacement field of the type $\{110\}<1 \overline{1} 0\rangle$ involved in the $\mathrm{V}$-shaped images. Among the various indications of the $\langle 110\rangle^{*}$ relrods as streaks around diffraction spots, streaks along $\langle 112\rangle$ around $\{1 \overline{3} 3\}$ spots are shown in Fig. 2(a). Note the absence of streaks in $\pm[01 \overline{1}]$ direction for the $\{1 \overline{3} 3\}$ spots, as this extinction confirms that the $\langle 110\rangle *$ relrods are derived from the static displacement field but not from the shape factor due to platelets of the tetragonal phase or precipitates.

Apart from the $\langle 110\rangle^{*}$ relrods, $\{110\}^{*}$ relwalls appear to exist, in that there are $\left.2 / 3<112\right\rangle *$ extra spots observed in [111] zones, Fig. 2(b). Three $\{110\}^{*}$ relwalls intersect at $\left.2 / 3<112\right\rangle *$ in [111] zones to cause an appreciable intensity. In addition, weak extra spots at $\langle 110\rangle *$ in $\langle 100\rangle$ zones and very weak streaks connecting diffraction spots in $<011\rangle$ zones have been observed, as the indications of the $\{110\}^{*}$ relwalls [9]. The origin of the $\{110\}^{*}$ relwalls in fec crystals is ascribed to the dynamic displacement of atomic chains along the close-packed $\langle 110\rangle$ directions [11]. The examination of the image and diffraction characteristics of aged $\mathrm{Cu}-\mathrm{Mn}$ alloys leads to the conclusion that both static and dynamic $\{110\}<1 \overline{1} 0>$ shear waves exist underlying the V-shaped microstructure.
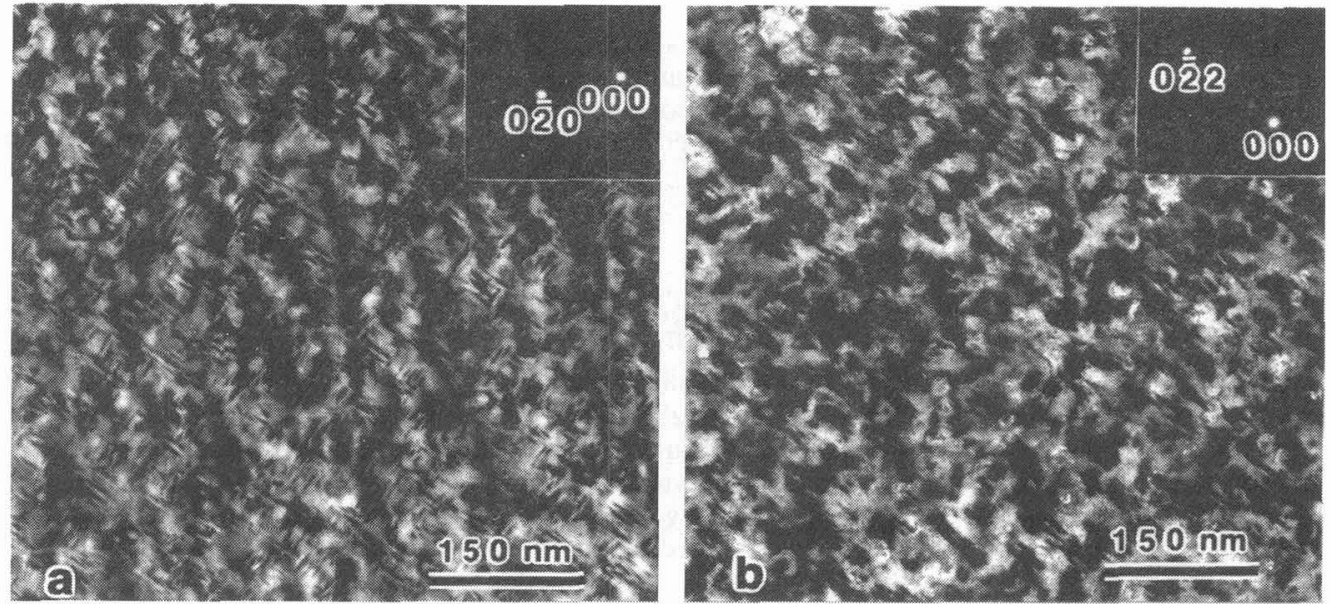

Fig. 1. V-shaped images observed in a $\mathrm{Cu}-\mathrm{Mn}$ alloy aged at $723^{\circ} \mathrm{K}$ for 10 hours. taken at two-beam excitation near [100] direction. 

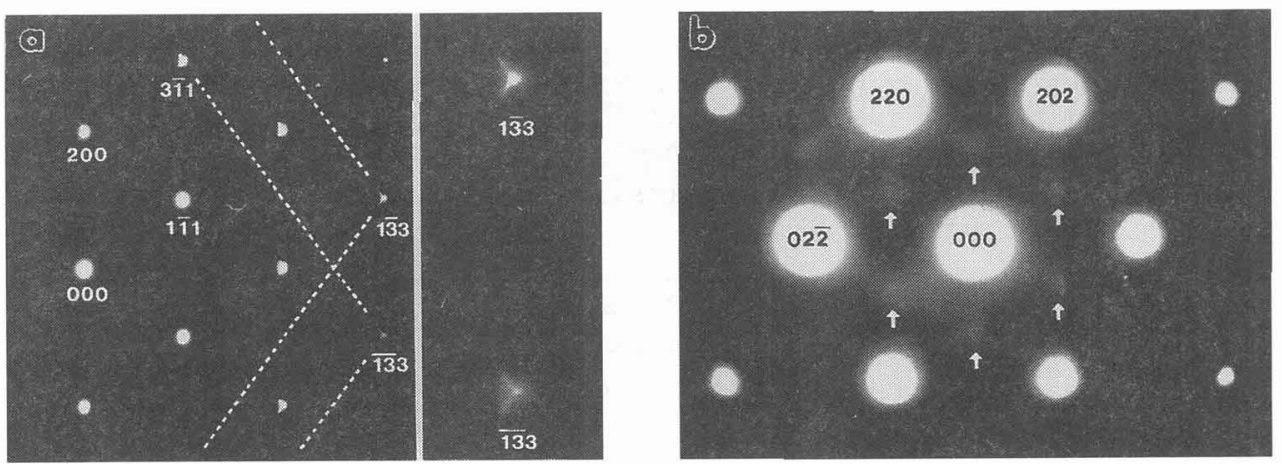

Fig. 2. $\mathrm{SAD}$ pattems indicating the presence of (a) $<110>^{*}$ relrods as streaks in [011] zone and (b) $\{110\}^{*}$ relwalls as extra spots in $[\overline{1} 11]$ zone.

\subsection{Dynamical "flickering" effect and microanalysis}

In the V-shaped images the most distinctive "flickering" activity was observed, although it was observed in the tweed images as well. Various movements observed in the $V$-shaped morphologies are shown schematically in Fig. 3. The flickering effect consists of spacially consistent and repetitive contrast variations. The regions which flicker are around $5 \sim 20 \mathrm{~nm}$ in size. Under certain diffraction conditions this dynamical movement was converted to an "on-off" nature in dark field images, so that it could be recorded in micrographs taken successively, as shown in Fig. 4. Here, bright spotty contrasts appear or disappear from place to place with elapsing time during observation, indicating clearly the dynamical movements taking place in the specimen.

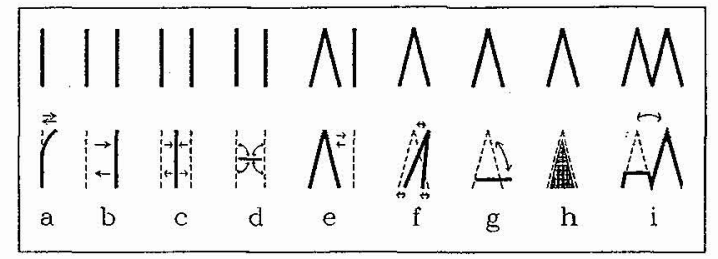

Fig. 3. Schematic diagram of flickering. Upper and lower diagrams indicate the images before and after a change of contrast.
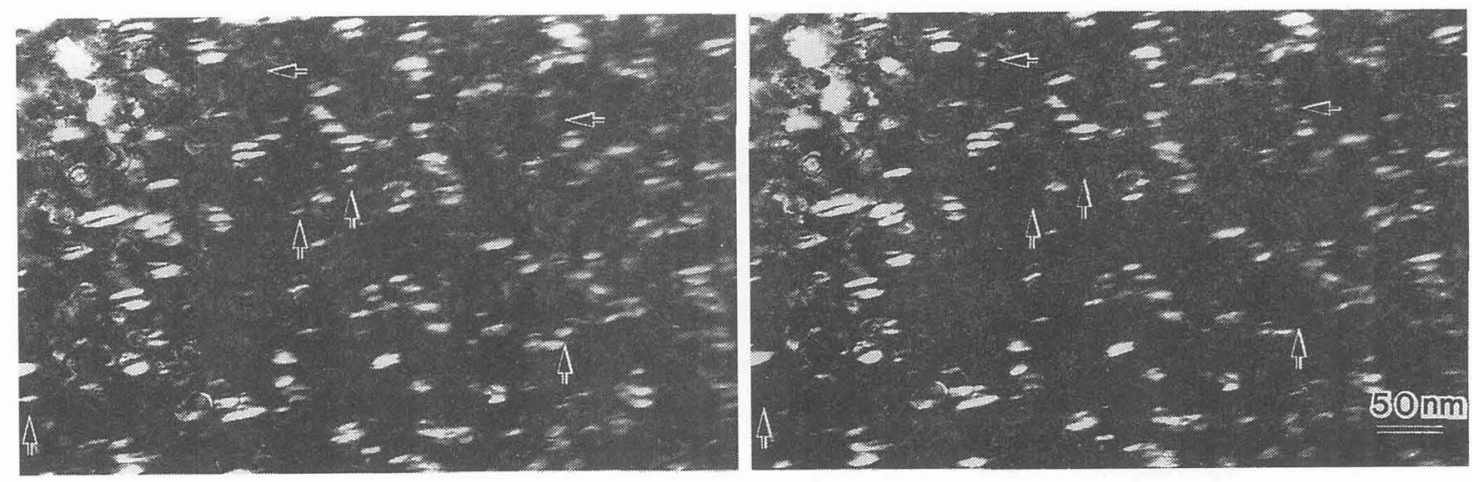

Fig. 4. Dark-field images taken successively in a $\mathrm{Cu}-\mathrm{Mn}-\mathrm{Al}$ alloy aged at $723^{\circ} \mathrm{K}$ for 10 hours. Flickering bright spots are indicated. 
Figure 5 shows TEM-EDX profiles taken from the matrix and the V-shaped region, respectively. The Mn concentration in the V-shaped region is clearly higher than in the matrix. Since these V-containing regions are embedded in the matrix, the actual $\mathrm{Mn}$ concentration is probably much higher than measured. When the $\mathrm{Mn}$ concentration is greater than $80 \mathrm{wt} \%$, fct martensite is reputed to be stable at room temperature [4]. When constrained in very small coherent segregated volumes, the $\mathbf{M}_{\mathbf{S}}$ temperature may well be modified. Thus, the Mn-enriched colonies are considered to be capable of transformation fcc $\Rightarrow$ fct with the progress of the phase separation.

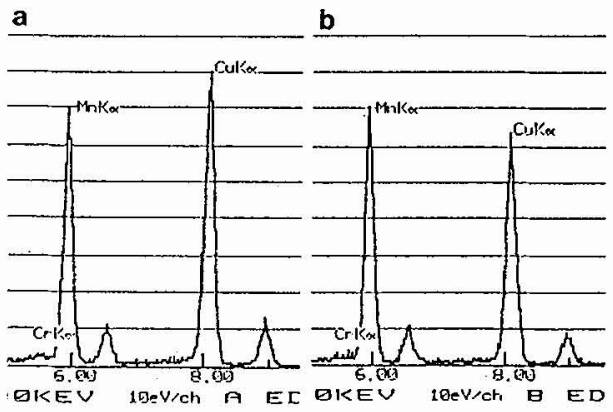

Fig. 5. EDX profiles of $\mathrm{Cu}$ and $\mathrm{Mn}$ for (a) matrix and (b) V-shaped regions. Sample aged at $723^{\circ} \mathrm{K}$ for 10 hours.

TEM-specimen surface topography was examined by using atomic force microscopy (AFM). As supposed from the difficulty of electropolishing or ion-milling to obtain a brilliant surface, AFM inspection of a well-polished surface yet revealed a corrugated surface with a maximum height gap around $10 \mathrm{~nm}$ or so, as shown in Fig. 6. This type of microirregularity is assumed to result from different etching rates of $\mathrm{Mn}$-rich and Mn-poor regions along a specimen surface during electropolishing. Protruding portions of the surface are assumed to be Mn-rich if referred to the results of SIMS measurements, Fig. 7. The yield of Mn ions decreases and that of $\mathrm{Cu}$ ions increases as primary $\mathrm{Cs}^{+}$ions induce sputtering into the depth of the specimen. Thus, from the sectional surface profile of AFM in Fig. 6 the Mn-concentration modulation is estimated to be on the scale of $30-80 \mathrm{~nm}$. This gives the size of the Mn-enriched colonies to be around 15$40 \mathrm{~nm}$.
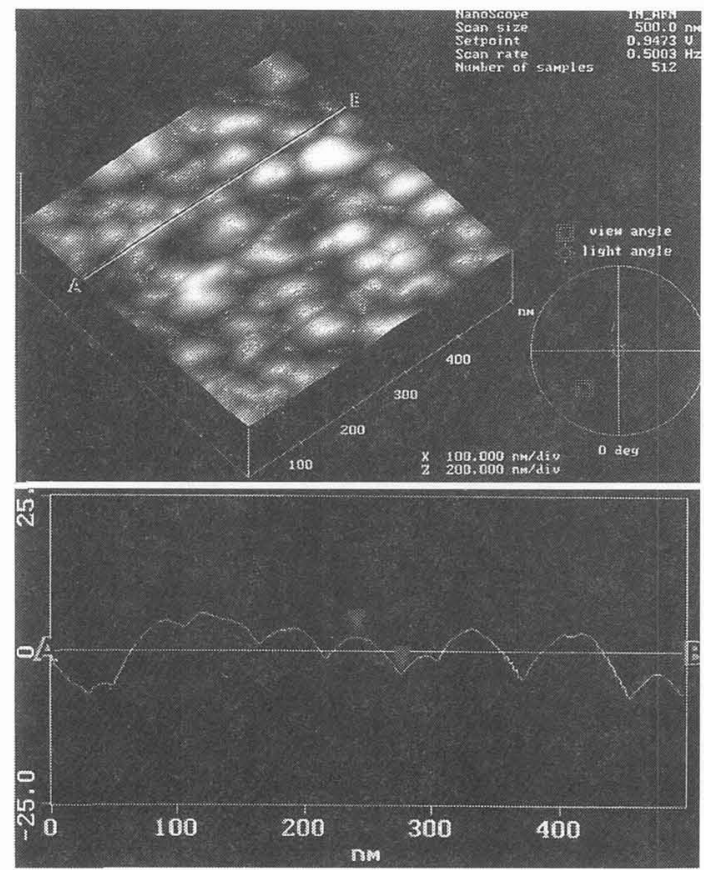

Fig. 6. AFM image of TEM-foil surface and line scan profile across points $A$ and $B$. Sample aged at $723^{\circ} \mathrm{K}$ for 10 hours.

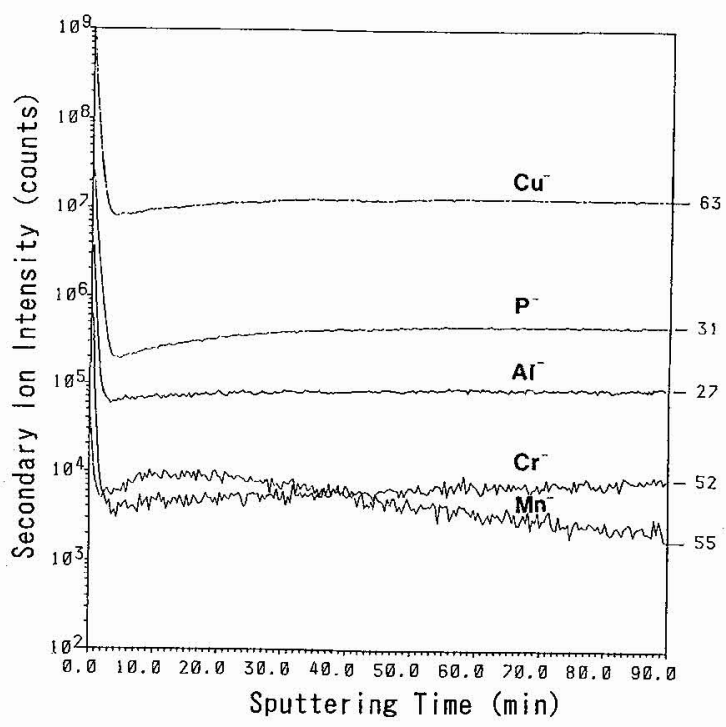

Fig. 7. Depth profile of secondary ions in SIMS surface analysis. Sample aged at $723^{\circ} \mathrm{K}$ for 10 hours. 
From these observations it follows that each bright spot in the dark field images of Fig. 4 corresponds to an fct crystallite confined in the segregated Mn-rich colony, the bright spot being produced because the slight misorientation of the fct crystallites causes stronger diffraction of the beam than does the surrounding matrix. In Fig. 4 the fct crystallites are sized 5-40 nm, aligned in similar orientation, and appear to exist in groups with gaps between them. This observation is suggestive that in the $\mathrm{Mn}$-rich colonies fct crystallites of different orientation are arranged alternately, in similar fashion to the self-accommodating pairs that occur in martensitic microstructures.

Figure 8 shows a high resolution TEM image of $\mathrm{V}$-shaped regions observed from the [011] direction. Various lattice planes are noticed to be rotated and curled at many locations. Although this effect can be partly attributed to the aforementioned thickness variations, some of these fringe modifications, such as those seen in the encircled area, may be caused by the presence of fct crystallites of different c-axis orientations.

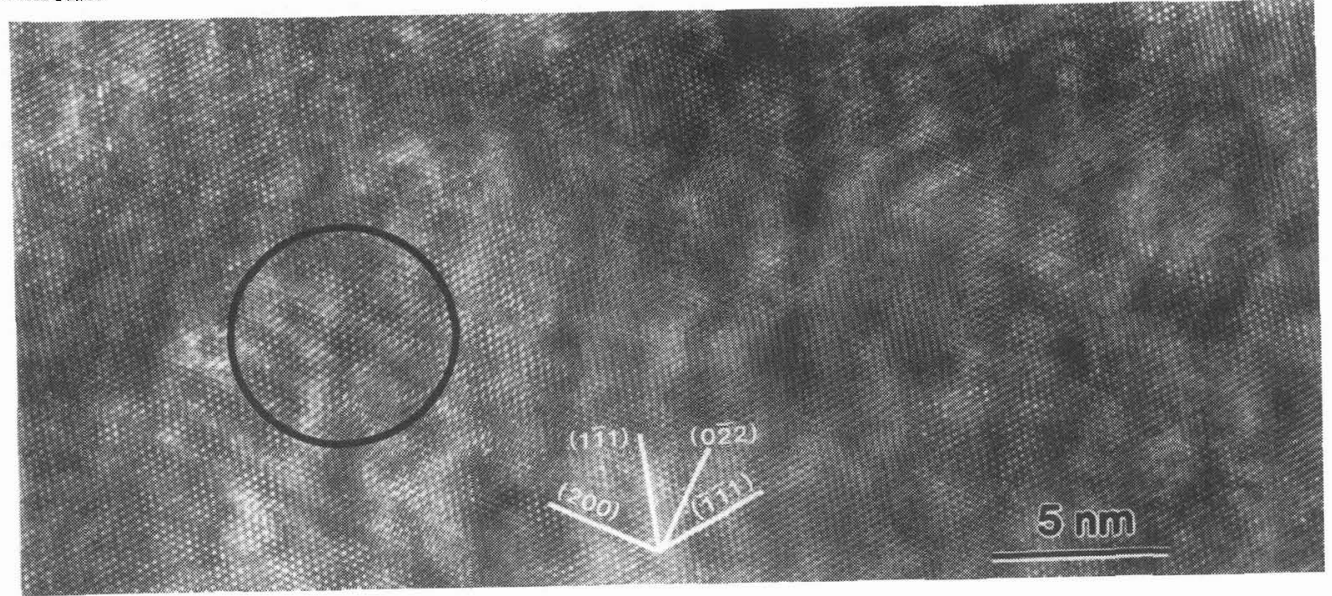

Fig. 8. HREM image observed in [011] orientation showing irregular lattice planes due to surface irregularities and to possible involvement of fct crystallites. Region of significant rotation of $(\overline{1} \overline{1} 1)$ is encircled.

\subsection{Mechanism of "flickering"}

In $\mathrm{Cu}-\mathrm{Mn}$ alloys of near-stoichiometric composition, aging within the miscibility gap activates decomposition of the $\gamma$-phase into $\mathrm{Mn}$-rich and $\mathrm{Cu}$-rich fractions and produces a microstructural modulation, as shown schematically in Fig. 9. When the Mn-enrichment is sufficient in the segregated colonies, the twinned fct phase is supposed to develop in a self-accommodating manner. The tetragonality gradually decreases to naught in the transient area around the Mn-rich colony. Therefore, the twin boundary, which should otherwise have formed on $\{110\}$, greatly deviates from $\{110\}$ and tapers in the Mn-rich colony to lead to the V-shaped morphology. Across the V-delineations are crystals of alternating c-axis directions.

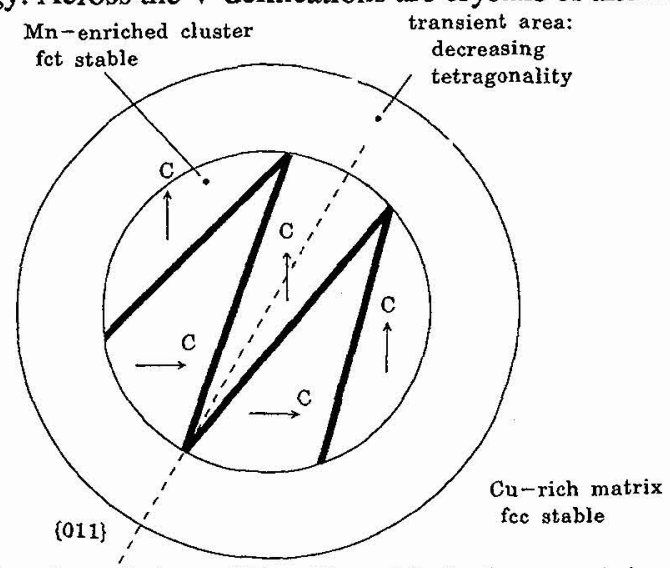

Fig. 9. Assumed structure of the V-shaped morphology within a Mn-enriched colony, consisting of fct crystallites of alternating c-axis directions. 
With the segregated microstructure as described, the dynamical flickering movements may be postulated as the rotation of the tetragonal axis, displacement of twin boundaries, and the transnformation event between $\mathrm{fcc}$ and $\mathrm{fct}$, all taking place in the Mn-rich colonies. The driving force to initiate these events is supplied from the electron-phonon interaction as follows. The elastic constant $\mathrm{C}^{\prime}=\left(\mathrm{C}_{11}-\mathrm{C}_{12}\right) / 2$ of $\mathrm{Mn}$-rich $\mathrm{Cu}-\mathrm{Mn}$ alloys is reported to decrease significantly as the temperature decreases toward the phase transformation temperature $[12,13]$. The presence of high-amplitude transverse acoustic waves with wave vector $\widetilde{\mathrm{q}} / /<110>$ and displacement vector $\tilde{\mathrm{e}} / /<1 \overline{1} 0>$ is likely, especially in the segregated Mn-rich colonies in the present alloys. Thus, we may envision that the accelerated electrons of $100-200 \mathrm{keV}$ would inelastically interact with the lattice to induce phonons of $0.01-0.1 \mathrm{eV}$. The induced $\langle 110\rangle\langle 110\rangle$ phonons would couple and cause in effect simultaneous double shears of $\{110\}<1 \overline{10}>$ which produce the fcc $\Rightarrow \mathrm{fct}$ phase transformation according to the Bowles-Barrett-Gutmann double shear theory [14]. Moreover, the couplings of $<110><1 \overline{10}>$ phonons are related to the rotation of $\mathrm{c}$-axis according to their combination. For example, coupling of the [101][10I] and [011][01I] phonons would cause the c-axis contraction to produce the $f \mathrm{fc} \Rightarrow \mathrm{fct}$ transformation, whereas if the [011][01I] phonon is absorbed and the [110][110] phonon is excited the c-axis of this fet would be rotated by 90 degrees. This mechanism of flickering is summarized in Table 1.

Table 1 Interpretation of the Mechanism of Flickering

\begin{tabular}{lll}
\hline Phonon Interaction & Crystallographic Change & Flickering Mode \\
{$[101][101]+[011][01 I] \equiv \mathrm{P}_{1}$} & $\mathrm{fcc} \Rightarrow$ fct forward transformation & creation, displacement \\
$\mathrm{P}_{1}-[101][10 \mathrm{I}]-[011][01 \mathrm{I}]$ & $\mathrm{fct} \Rightarrow$ fcc reverse transformation & disappearance, displacement \\
$\left.\mathrm{P}_{1}-[011][01 \mathrm{I}]+[110][1] 0\right]$ & fct c-axis reorientation & rotation \\
\hline
\end{tabular}

\section{Acknowledgments}

The authors wish to thank S. Iida and Y. Otsuka for conducting HREM and AFM observations.

\section{References}

[1] Smith, J.H. and Vance, E.R., J. Appl, Phys. 40 (1969) 4853-4858.

[2] Vintaykin, Y.Z., Litvin, D. F. and Udovenko, V.A., Phys. Metall. Metallog. 37 (1974) 1228-1237.

[3] Vitek, J.M. and Warlimont, H., Metal Sci. J. 10 (1976) 7-13.

[4] Basinski, Z.S. and Christian, J.W., J. Inst. Metals 80 (1951-52) 659-666.

[5] Butler, E.P and Kelly, P.M., Trans. AIME 242 (1968) 2099-2106, 2107-2109.

[6] Bacon, G.E. et al, Proc. Roy. Soc. London, Series A 241 (1957) 223-238.

[7] Perkins, J., Mayes, L.L. and Yamashita, T., Scripta Metall. 22 (1988) 887-892.

[8] Perkins, J. et al, "Premartensitic Transitions in Aged Cu-Mn Alloys", MRS International Meeting on Advanced Materials, Symposium H, Tokyo, Japan, May 30-June 3, 1988 (Materials Research Society, Pittsburgh, Pennsylvania, 1989) pp. 43-48.

[9] Adachi, K., Yamashita, T., Taneda, Y., Farkas, D.M. and Perkins, J., submitted to Phil. Mag. (1995).

[10] Tanner, L.E., Phil. Mag.,14 (1966) 111-130.

[11] Honjo, G., Kodera, S. and Kitamura, N., J. Phys. Soc. Japan 19 (1964) 351.

[12] Vintaykin, Y.Z, et al, "The Premartensitic Instability of FCC $\gamma$-Mn-Based Alloys", International Conference on Martensitic Transformations, Nara, Japan, August 26-30, 1986 (Japan Institute of Metals, Tokyo, 1986) pp. 121-126.

[13] Tsunoda, Y., Oishi, N. and Kunitomi, N., Physica 119B (1983) 51-55.

[14] Bowles, J.S., Barrett, C.S. and Guttmann, L., Trans. AIME 188 (1950) 1478-1485. 